\title{
Os resorts residenciais na região metropolitana de Fortaleza (Ceará, Brasil)*
}

\author{
Residential resorts in the metropolitan area of Fortaleza (Ceará, Brazil)
}

\author{
Marília Natacha de Freitas Silva (SILVA, M. N. de F.) ${ }^{* *}$
}

RESUMO - O presente artigo tem por objetivo analisar o processo crescente de expansão e expressão dos resorts residenciais na região metropolitana de Fortaleza (Ceará, Brasil), tomando como pano de fundo, a importância das políticas públicas nesse processo. Para o alcance dos objetivos realizou-se análise dos investimentos públicos que garantem suporte ao turismo e sua implicação ao processo que se traduz na expansão e urbanização de Fortaleza, assim como a análise dos investimentos privados, muitos de ordem estrangeira, que são atraídos por políticas provenientes do Estado do Ceará, investimentos operados em grandes resorts residenciais. Portanto a metodologia do trabalho consistiu em levantamento e análises estatísticas, produção cartográfica e trabalho de campo. Como resultados preliminares de um projeto ainda em andamento diagnosticou-se um processo de expansão da metrópole de Fortaleza, através da adoção de políticas públicas, como o Programa de Desenvolvimento do Turismo (PRODETUR / I, II e Nacional), Programa de Aceleração do Crescimento (PAC) e a atração de investimentos privados direcionados a grandes resorts, em sua maioria investimentos estrangeiro aplicados aos municípios litorâneos do litoral leste e oeste do estado do Ceará.

Palavras-chave: Metropolização; Políticas públicas de turismo; Resorts residenciais.

ABSTRACT - This paper has its goal to analyze the process of expansion and increased expression of resort residences in the metropolitan area of Fortaleza (Ceará, Brazil), taking the background, the importance of public policies in this process. To achieve the objectives of the study, it was analyzed the public investments that provide support to tourism and its implication to the process that resulted in expansion and urbanization of Fortaleza, as well as the analysis of private investments, many of them from foreigners, who are attracted by policies from the state of Ceará, these investments operated in large residential resorts. Therefore the methodology of this study consisted of surveys and statistical analyses, cartographic production, and field work. As preliminary results of a project still in progress, it was diagnosed a fast process of expansion in the metropolitan area of Fortaleza, with the adoption of public policies as PRODETUR - Tourism Development Program (Prodetur I, II, and National), PAC Growth Acceleration Program, and the attraction of private investments directed to the big resorts, mostly with foreign investments applied to the coastal cities of Ceará.

Key words: Metropolization; Tourism public policies; Residential resorts

\footnotetext{
* Trabalho desenvolvido com recursos do Projeto Milênio, no âmbito do Observatório das Metrópoles (Núcleo Fortaleza), no período da Graduação.

** Graduação em Geografia (Licenciatura) pela Universidade Federal do Ceará - UFC. Mestranda em Geografia (UFC). Pesquisadora da rede Observatório das Metrópoles - núcleo LAPUR (Laboratório de Planejamento Urbano e Regional)/Fortaleza - Ceará (CE). Endereço para correspondência: Rua Cesário Lange 820. CEP: 60841-220 - Fortaleza - Ceará (Brasil). Telefones: 85-3276-2864/85-8801-3014. Email: mnsilva.ufc@gmail.com
} 


\section{INTRODUÇÃO}

Em meio às mudanças de ordem política, iniciadas em meados da década de 80 , o Estado do Ceará passa então por um processo de reordenamento territorial culminando em grandes mudanças socioespaciais (SILVA, 2010). No litoral cearense tais transformações posicionaram-se através do desenvolvimento da atividade turística e de veraneio que receberam grandes incentivos, tanto de políticas públicas como privadas.

Desde a década de 80 o turismo no Ceará intensificou-se graças aos investimentos públicos (oriundos do Estado) e investimentos privados (resorts) estes últimos de origem de capital estrangeiro, principalmente espanhol e português (MELO e SILVA; CARVALHO; SILVA, 2009).

Levando em conta que as segundas residências possuem papel importante nos processos de expansão urbana e metropolização da capital fortalezense para áreas vizinhas e que os resorts têm importância na captação de investimentos estrangeiros, o presente estudo possui como objetivo analisar o processo crescente de expansão e expressão dos resorts residenciais na metrópole de Fortaleza, tomando como pano de fundo, a importância das políticas públicas nesse processo.

A pesquisa como análise do mercado de segundas residências nos resorts pautou-se dentro dos municípios litorâneos da Região Metropolitana de Fortaleza RMF, em especial ao Aquiraz, já que este em análises estatísticas mostrou-se como o receptor maior da parcela de empreendimentos privados no Estado do Ceará. A análise deste fenômeno torna-se um diferencial para o entendimento acerca das reflexões de ordem estruturais e/ou governamentais que circunscrevem o modelo de funcionamento da região em estudo - RMF - a partir do momento em que há um direcionamento de políticas públicas de turismo em favorecimento desses empreendimentos residenciais.

Tendo em vista as políticas públicas direcionadas ao turismo nos últimos governos, verifica-se a adoção de investimentos maciços em urbanização, tanto na figura dos Programas de Desenvolvimento do Turismo (PRODETUR /I e II) como investimentos do Programa de Aceleração do Crescimento (PAC).

Além de investimentos públicos, os municípios litorâneos da metrópole, apresentam uma crescente entrada de investimentos privados de capital externo investidos em sua grande maioria em empreendimentos de resorts residenciais, sendo esses investimentos públicos e privados destinados para o turismo e veraneio. 
De acordo com Dantas et al. (2009), tomando a Vilegiatura Marítima (na expressão das segundas residências) como um fenômeno causador e impulsionador de expansão urbana, em relevância no litoral cearense, torna-se essencial a compreensão da ação de políticas públicas adotadas nos últimos anos, como também a compreensão do crescente volume de investimentos estrangeiros privados em decorrência da hibridação entre as atividades turísticas e as atividades de veraneio nos Resorts.

Para compor o estudo, a realização das seguintes etapas foi essencial: levantamento bibliográfico, momento de estudo e reflexão de assuntos referentes às políticas públicas de turismo PRODETUR e PAC, às segundas residências, ao veraneio, ao turismo, aos Resorts residenciais, além de um levantamento documental junto às instituições públicas, à Secretaria de Meio Ambiente/CE (SEMACE) e à Secretaria de Turismo/CE (SETUR) e a realização de um trabalho de campo nas praias de Aquiraz: Porto das Dunas e Prainha, com a finalidade de identificar os resorts e compreender a dinâmica turística de um Resort.

Assim o presente estudo consiste no desígnio de uma análise das políticas públicas junto aos investimentos privados ocorrentes em especial nos últimos dez anos no Estado do Ceará, assim como também tem o intento de identificar as mudanças sócio-espaciais na RMF.

\section{O PAPEL DAS POLÍticas PÚbliCAS DE TURISMO PARA CONSOLIDAÇÃO DO TURISMO E DO IMOBILIARIO NA METRÓPOLE}

Ao pensar em atração de investimentos privados ao nordeste brasileiro faz-se necessário pensar a lógica do Estado e suas políticas para atrair estes investimentos que serão apresentadas posteriormente, como as políticas públicas que investem continuamente nos espaços litorâneos da metrópole. Em um retrospecto das políticas públicas voltadas para o turismo verifica-se segundo Coriolano (2006) que a década de 1980 constitui-se como marco nas mudanças de ordenamento territorial do Estado, principalmente no governo de Tasso Jereissati (1987-1991) e seus sucessores, período no qual, a imagem do Ceará propaga-se no cenário turístico internacional. 
Apenas, com políticas públicas voltadas para o turismo e autonomia do governo local (ruptura com a política dos coronéis) juntamente com a reformulação da imagem turística do Estado, ocorrem grandes transformações e processos de reordenamento territorial onde muda a racionalidade de um ordenamento sertão-porto (interior-capital) e passa a se pautar em uma ordenação aeroporto - vias litorâneas (paralela à zona de praia), conforme Dantas (2009).

Com a diminuição do poder do Estado Nacional, os Estados locais se fortalecem e se fazem novos protagonistas nos seus territórios, traçando objetivos e metas com a finalidade de captar recursos estrangeiros, criando assim uma corrida entre os Estados, principalmente na região Nordeste do Brasil. Segundo Coriolano (2006), torna-se necessário o empenho do Estado e das empresas em divulgar sua imagem e produtos no exterior resultando em ações públicas e investimentos privados.

O Ceará com o intuito de atrair investimentos privados para seu território precisava de condições básicas de infraestrutura, o que foi possível graças a programas públicos de ações para o turismo.

Segundo dados do Banco do Nordeste Brasileiro (BNB, 2010), o programa PRODETUR I investiu R\$ 900 milhões nos Estados do Nordeste Brasileiro, capital oriundo tanto do Banco Interamericano de Desenvolvimento (BID), quanto de contrapartida dos próprios Estados da Federação e do Governo Federal. No Ceará a previsão era receber 160 milhões, ao final foi investido em torno de 166 milhões (BNB, 2010). Na mesma fonte consta que tais investimentos tiveram sua aplicação em infraestrutura, como: construção e reparação de rodovias, saneamento básico, aeroportos, capacitação profissional e urbanização em orlas e áreas turísticas.

Constatou-se que referente ao PRODETUR II, o Nordeste recebeu um montante de $\mathrm{R} \$ 710$ milhões, sendo destes, uma soma de 152 milhões repassada para o Ceará, ou seja, 20\% do total direcionado a Região Nordeste. E ainda consta que dos 152 milhões arrecadados foram investidos $55 \%$ em transporte e $20 \%$ em saneamento. Os outros $25 \%$ foram investidos em outros componentes do PRODETUR II.

Tais investimentos foram de suma importância para a ocupação e dinamização do litoral oeste, seguimento pouco ocupado até década de 90, mas que teve com o PRODETUR a oportunidade de entrar no cenário nacional e internacional, além de atrair investimentos privados, em especialmente em áreas como a região metropolitana e 
litorânea do Ceará (ARAUJO, 2009). Segundo Dantas (2009), o PRODETUR contribuiu nos processo de urbanização e valorização dos espaços litorâneos, processos cruciais para a consolidação das práticas marítimas modernas.

O quadro de investimentos não se restringe apenas aos números acima mencionados. Como resultado das pesquisas realizadas nos bancos de dados da Comissão de Financiamento Externo - CONFIEX (2011) e dos relatórios do PAC (2010) mostrou-se que os programas do PRODETUR Nacional e PAC 2007-2010, investiriam o montante de $\mathrm{R} \$ 550$ milhões e $\mathrm{R} \$ 3,2$ milhões respectivamente no Estado do Ceará.

O PRODETUR NACIONAL é um programa regional de desenvolvimento do turismo, que veio complementar o PRODETUR I e II, programas lançados ainda na década de 90 e início dos anos 2000 respectivamente (ARAUJO, 2009). Segundo o Ministério do Turismo (s/a), o programa que teve seu lançamento no governo Lula em 2008, com financiamento inicial de 1,6 bilhões de dólares visa aumentar a competitividade dos destinos turísticos do país e consolidar a política de turismo nacional por meio de um modelo de gestão pública descentralizada e cooperativa.

O programa possui ações regionais, estaduais e municipais, ou seja, os próprios Estados da Federação possuem autonomia para escolher a carta de crédito de financiamento e as localidades beneficiadas (SILVA, 2010). Entretanto, para conquistar uma carta de crédito do BID ou da Confederação Andina de Financiamento (CAF), os Estados e Municípios deviam elaborar suas próprias cartas-consulta, contendo objetivos, metas, orçamento e a aplicação dos investimentos por área, além disso, após as aprovações das cartas, os estados precisam iniciar as obras com o dinheiro do tesouro estadual ou municipal para assim efetivar e receber a quantia total do financiamento (SILVA, 2010).

No que tange ao PRODETUR NACIONAL (2010-2015), o Ceará se destaca tanto em sua presteza na produção da carta consulta, como sendo o Estado que conquistou a maior quantia de investimento do programa, como pode ser observado na Figura 1. Segundo a Confiex (2011) o governo do estado do Ceará investirá nas regiões turísticas, em cinco anos, (2010-2015), um montante de 350 milhões que supera todas as outras cartas consultas. 
De acordo com a figura abaixo, entre os Estados com cartas já aprovadas, temse: Ceará (CE), Pernambuco (PE), Rio Grande do Norte (RN), Paraíba (PB), Sergipe (SE), Piauí (PI), e por último, os Estados da Bahia (BA) e do Maranhão (MA), ou seja, dos nove Estados nordestinos, oito possuem cartas consultas já aceitas; apenas o Estado de Alagoas (AL) até o momento não recebeu investimento do programa (CONFIEX, 2011).

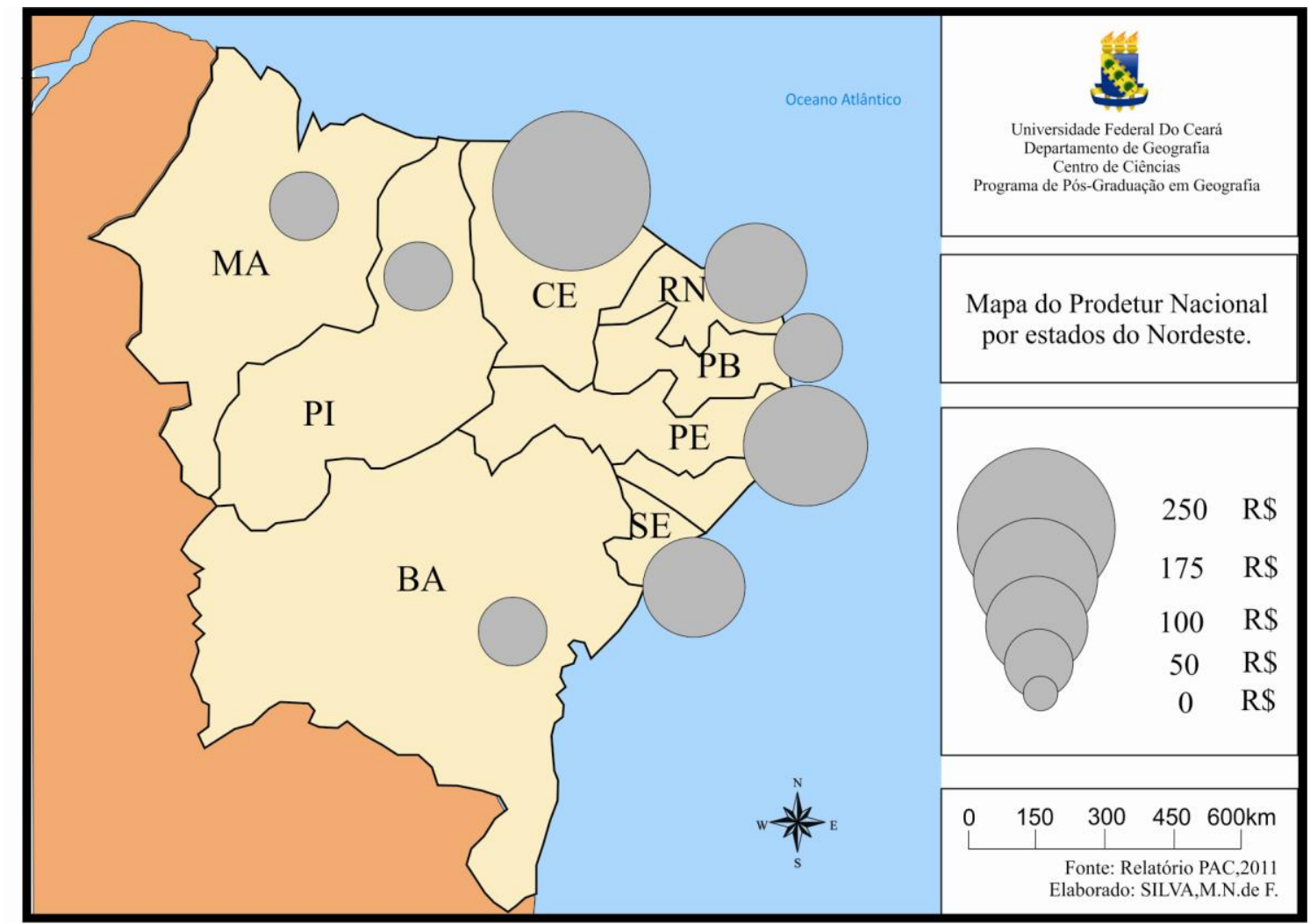

FIGURA 1 - INVESTIMENTOS PREVISTOS DO PRODETUR NACIONAL POR ESTADO; FONTE: CONFIEX, 2011.

ELABORADO POR: SILVA, M. N. de F. (2012).

As cartas-consultas dos Estados do Nordeste já aprovadas somam um capital de US\$ 700,00 milhões (contrapartida + financiamento), portanto, tomando como base os dados apresentados na figura 1, o dinheiro será repartido de forma decrescente: US\$ 250,00 milhões para o Ceará; US\$ 125,00 milhões para Pernambuco; US\$100,00 milhões para Sergipe; U\$ 85,00 milhões para a Bahia; US\$ 75,00 milhões para Rio Grande do Norte; US\$ 50,00 milhões para Piauí e Maranhão; e US\$ 38,00 milhões para a Paraíba (CONFIEX, 2011). 


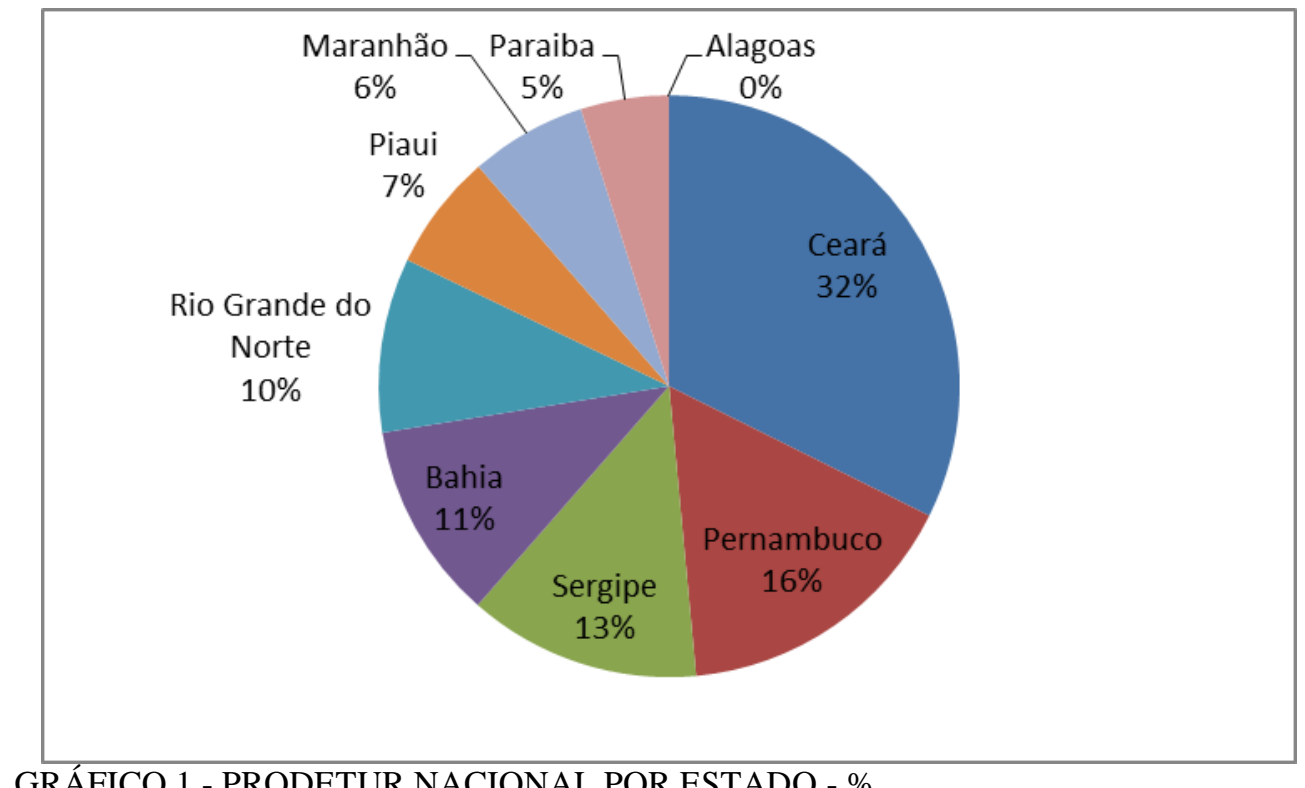

GRÁFICO 1 - PRODETUR NACIONAL POR ESTADO - \%.

FONTE: CONFIEX (2011).

De acordo com o gráfico acima, dentro dos Estados do Nordeste que tiveram suas cartas aprovados, Ceará e Pernambuco são os maiores receptores, do total dos recursos aprovados pelo PRODETUR NACIONAL do Nordeste, com 32\% e 16\% respectivamente. Há importância de destacar, segundo dados coletados e apresentados anteriormente (gráfico 1), o Estado do Sergipe, que entrou com uma contrapartida de US\$ 60,00 milhões e um financiamento de 40 milhões, mostrando atual preocupação em consolidar-se como destino turístico, angariando $13 \%$ do valor total do PRODETUR Nacional do Nordeste (CONFIEX, 2011).

O Ministério do Turismo (s/a) menciona que o Ceará, investirá com o PRODETUR Nacional: no Litoral Leste, Cariri e Serra da Ibiapaba, assim como em alguns municípios: Juazeiro do Norte, Cascavel, Fortim, Beberibe, Aracati, entre outros, além de capacitação profissional e empresarial e recuperação do patrimônio histórico. De acordo com informações da Secretaria de Turismo do Ceará (SETUR/CE, 2012) algumas das obras já tiveram inicio, como a duplicação da CE 040, estrada para Beberibe - Praia das fontes e saneamento e abastecimento no litoral leste, como outras obras.

Visto os investimentos oriundos do PRODETUR Nacional, segue adiante a discussão acerca do PAC. Este programa foi lançado em 28 de janeiro de 2007, pelo Governo Federal em abrangência nacional. Segundo o relatório do PAC (2010), o 
programa prevê um investimento total de $\mathrm{R} \$ 503,9$ bilhões de reais, que serão gastos prioritariamente em transportes e infraestrutura, em energia e em habitação e saneamento. De acordo com os dados quantitativos retirados do relatório PAC no Ceará, os gastos para apoiar o turismo são na maioria em rodovias, aeroportos e transporte, uma soma de R\$ 61,7 milhões. Nos Estados brasileiros, concentrando maior parte dos investimentos que serão gastos na Região Nordeste e na Região Sudeste do país (PAC, 2010).

Tomando como base os dados coletados e sistematizados pela autora, a partir dos relatórios do PAC por Estado, disponibilizados no site do Governo Federal, o programa investirá R \$ 8.174,1 bilhões só no Nordeste Brasileiro entre os anos de 20002007 e pós-2010 para apoio ao turismo, com obras de infraestrutura logística, como construções, ampliações e reformas de estradas e investimentos em aeroportos (figura 2). Deste capital, $\mathrm{R} \$ 3.500,7$ bilhões serão investidos no Estado da Bahia, obras em dois aeroportos, tendo uma construção de um aeroporto em Ilhéus e ampliação do aeroporto de Salvador e construções e adequações de rodovias federais, enquanto o Ceará, por sua vez, receberá investimentos para o aeroporto (PAC, 2010).

$\mathrm{O}$ investimento do PAC, no Nordeste, ao se concentrar em obras de infraestrutura logística, de investimentos em aeroportos e nas rodovias federais, conforme mencionado acima, são obras fundamentais para dinamizar os fluxos, consolidando, portanto o turismo no Nordeste. Em ordem decrescente se apresentam os investimentos na Região Nordeste, segundo a figura abaixo: Bahia com R\$ 3.500.7 bilhões; Alagoas, R \$ 1.648,00 milhões; Pernambuco, R\$ 1.265,9; Sergipe, R\$ 1.011,00 milhões; Paraíba, R\$ 600,4; Rio Grande do Norte, R\$ 84,0 milhões; Piauí, R\$ 32,8 milhões e por último o Estado do Ceará com R\$ 31,3 milhões (PAC, 2010). 


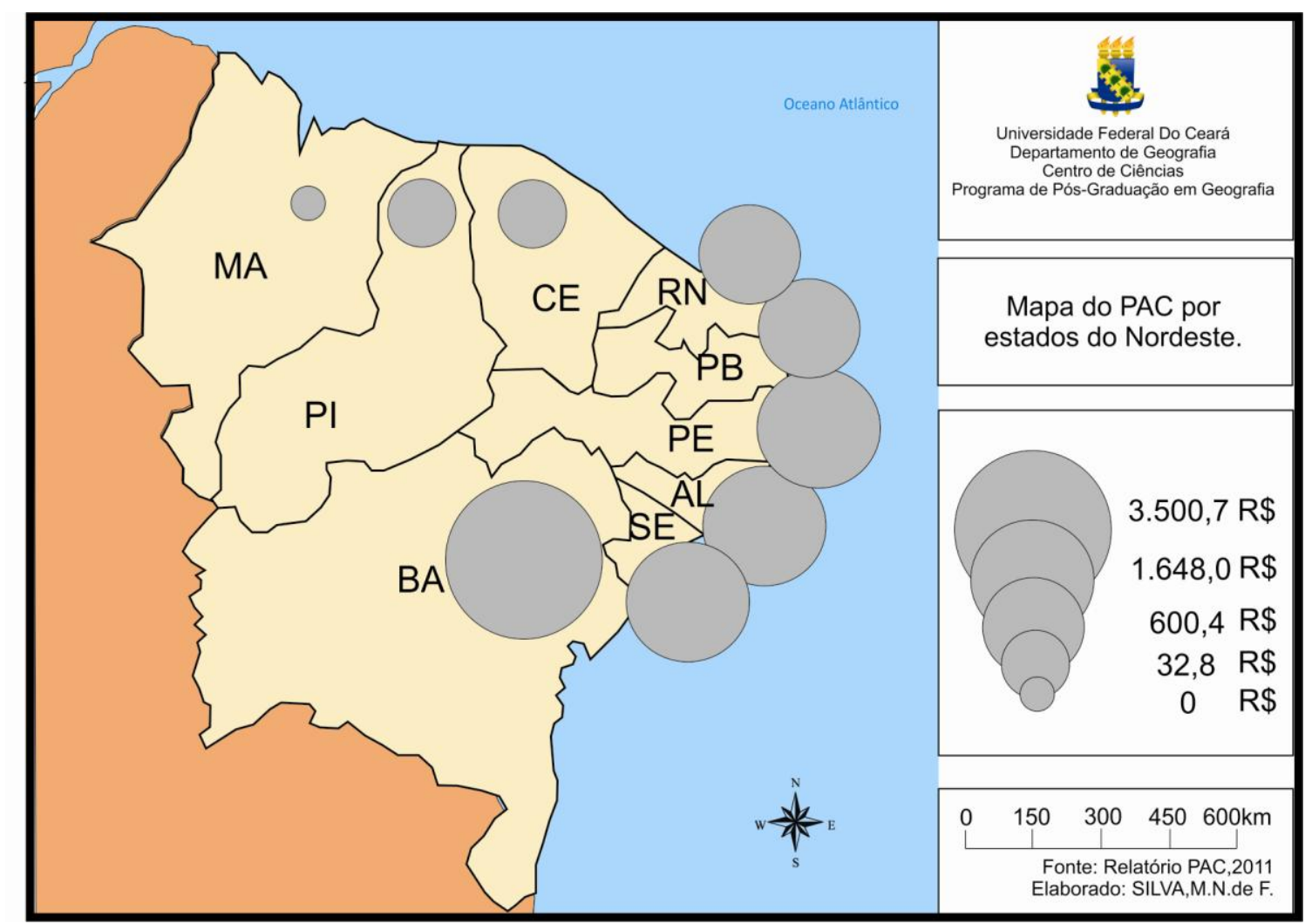

FIGURA 2 - INVESTIMENTOS PREVISTOS DO PAC POR ESTADO

FONTE: GOVERNO FEDERAL: RELATÓRIO PAC (2010), ELABORAÇÃO: SILVA, M. N. DE F.

A partir de tantos investimentos públicos, especialmente na zona costeira, com uma nova racionalidade de reordenamento territorial (aeroporto - vias litorâneas) existe uma lógica territorial de valorização litorânea. Diante disso, se julgou importante analisar a contrapartida privada. Como o Ceará se insere no mercado internacional? Que investimentos estão sendo atraídos? Quais mudanças sócio-espaciais? Qual o comportamento do setor imobiliário turístico nos últimos 10 anos?

\section{CAPITAL INTERNACIONAL: CONSIDERAÇÕES SOBRE OS RESORTS RESIDENCIAIS NA METRÓPOLE}

Como pôde ser analisado no tópico anterior, nas últimas décadas, o Ceará vivenciou muitas ações para o desenvolvimento turístico no Estado, onde foram feitos grandes investimentos em infraestrutura, principalmente no litoral oeste utilizando-se do PRODETUR, com a finalidade de inseri-lo no mercado internacional. O litoral leste 
também recebeu e recebe grandes investimentos de infraestrutura, junto ao PRODETUR NACIONAL.

Em meio a tantos investimentos públicos, o Ceará nas últimas décadas especialmente entre 2000-2012 teve seu mercado imobiliário aquecido com investimentos de origem estrangeira. Esta grande dinamização das atividades turísticas atrai grandes investimentos, tanto turísticos quanto associados às segundas residências, atividades operadas nos resorts.

O mercado imobiliário, com o objetivo de buscar uma maior competitividade e um mercado consumidor, diversifica seus produtos na tentativa de atrair diferentes públicos. Portanto os serviços hoteleiros acabam por se incorporar ao componente imobiliário, nos últimos anos aumentando suas receitas.

A presença dos Resorts aquece cada vez mais a especulação imobiliária, a valorização do espaço litorâneo, a expansão e a urbanização dos municípios litorâneos. Com a melhoria dos transportes, Mello e Silva; Carvalho; Silva (2009) afirmam que os resorts residenciais na última década aceleram essas atividades com a previsão de curto prazo de um processo em ritmo acelerado de mudanças socioespaciais. Mas o que seriam, portanto, os resorts residenciais?

Os resorts são empreendimentos de alto padrão, instalações e serviços, voltados para o lazer em áreas de contato com a natureza, nos quais o hóspede não precisa se afastar do hotel para ser atendido com conforto e entretenimento, conforme Guia de Resorts Brasileiros (2003).

Segundo o mesmo guia esses empreendimentos unem em seus serviços: lazer, restaurantes e hospedagem em um só espaço. Também que a estrutura deve conter, mas não necessariamente, quadra esportiva, piscina, golfe, centro de convenções, sauna, além de atividades de entretenimento e serviços hoteleiros de alta qualidade.

Este empreendimento para o Estado torna-se importante pelo fato de geração de impostos das segundas residências, além de serem importantes para o mercado imobiliário pela valorização dos terrenos e atração de investimentos estrangeiros.

Para entender a importância dos resorts residenciais como causa de mudanças socioespaciais no Ceará, é preciso entender a Vilegiatura (segundas residências) e o turismo litorâneo, ambos os fenômenos de valorização dos espaços litorâneos. A primeira como "expressão do tecido urbano em expansão" (DANTAS, 2009) e o 
segundo como consumidor destes espaços litorâneos. Estes dois fenômenos tornaram-se relevantes no cenário cearense em 1980 e 1990 respectivamente.

O mundo do turismo se moderniza a cada dia, une a prática turística ao veraneio (na figura dos resorts residenciais), onde as interseções destas práticas atraem cada vez mais investimentos privados. É possível analisar estas interseções no presente estudo na Região Metropolitana de Fortaleza e no Estado da Bahia, a partir do estudo de Mello e Silva; Carvalho; Silva (2009).

A partir da pesquisa feita pela autora, com base nos dados da SEMACE (2012), o Estado do Ceará possui um total de sete empreendimentos já instalados em operação nos municípios de Aquiraz e São Gonçalo do Amarante, sendo cinco destes instalados no município metropolitano e litorâneo do Aquiraz. Como podem ser observados na tabela, os empreendimentos são em sua maioria resorts residenciais, com casas unifamiliares ou multifamiliares, além da presença de hotelaria de rede. (ver quadro 1).

\begin{tabular}{|c|c|c|c|c|}
\hline \multicolumn{5}{|c|}{ RESORTS CONCLUÍDOS } \\
\hline \multicolumn{5}{|c|}{ Período: 1989 a 2008} \\
\hline Município & Empreendimentos & Atividades & Estrutura & Etapa \\
\hline Aquiraz & Beach Park Suítes & Veraneio/Turismo & 183 apartamentos & $\begin{array}{l}1988 \text { - } \\
\text { concluído }\end{array}$ \\
\hline Aquiraz & $\begin{array}{l}\text { Aquaville Resort \& } \\
\text { Hotel }\end{array}$ & Veraneio/Turismo & $\begin{array}{l}498 \text { residências / } 85 \\
\text { apartamentos }\end{array}$ & $\begin{array}{l}\text { 1997- } \\
\text { Concluído }\end{array}$ \\
\hline Aquiraz & $\begin{array}{l}\text { Oceani das dunas } \\
\text { resort }\end{array}$ & Turismo & 133 apartamentos & $\begin{array}{l}\text { 2000- } \\
\text { Concluído }\end{array}$ \\
\hline Camocim & Boa Vista Resort & Turismo & 123 apartamentos & $\begin{array}{l}2000- \\
\text { Concluído }\end{array}$ \\
\hline Aquiraz & $\begin{array}{l}\text { Beach Park Acqua } \\
\text { Resort }\end{array}$ & Veraneio/Turismo & 123 apartamentos & $\begin{array}{l}2008 \text { - } \\
\text { Concluído }\end{array}$ \\
\hline Aquiraz & Beach Park Living & Veraneio & 160 apartamentos & $\begin{array}{l}2009 \text { - } \\
\text { Concluído }\end{array}$ \\
\hline $\begin{array}{l}\text { São Gonçalo do } \\
\text { Amarante }\end{array}$ & Taíba Beach Resort & Veraneio/Turismo & $\begin{array}{l}\text { Apartamento/ casas } \\
\text { frente ao mar/ casas } \\
\text { duplex } \\
\text { Total: } 152 \mathrm{UHs}\end{array}$ & $\begin{array}{l}2009 \text { - } \\
\text { Concluído }\end{array}$ \\
\hline \multicolumn{5}{|c|}{ Resorts em fase de construção - Período 2000 - 2012} \\
\hline Município & Empreendimentos & Atividades & Estrutura & Etapa \\
\hline Aquiraz & $\begin{array}{l}\text { Empreendimento } \\
\text { Turistíco Praia Bela } \\
\text { Resort \& Village } \\
\text { (Aquiraz Riviera) }\end{array}$ & $\begin{array}{l}\text { Veraneio/ } \\
\text { Turismo }\end{array}$ & $\begin{array}{l}8 \text { hotéis / } 6 \text { pousadas } \\
\text { / } 600 \text { bangalôs/800 } \\
\text { residências/ } 615 \text { lotes }\end{array}$ & 2007- Fase 1 \\
\hline
\end{tabular}

Continua... 
Continuação...

\begin{tabular}{|c|c|c|c|c|}
\hline Aquiraz & $\begin{array}{l}\text { Complexo Turístico } \\
\text { Hoteleiro e de } \\
\text { Desenvolvimento } \\
\text { Urbano Barra do } \\
\text { Aquiraz }\end{array}$ & Veraneio/turismo & $\begin{array}{l}\text { Hotéis/condomínios/r } \\
\text { esidências/4 resorts }\end{array}$ & $\begin{array}{l}\text { Projeto } \\
\text { aprovado }\end{array}$ \\
\hline Aquiraz & $\begin{array}{l}\text { Resort Fortaleza Golf } \\
\text { Club }\end{array}$ & $\begin{array}{l}\text { Veraneio / } \\
\text { Turismo }\end{array}$ & $\begin{array}{l}\text { Hotéis/apartamentos } \\
\text { e chalés }\end{array}$ & Em estudo \\
\hline Caucaia & $\begin{array}{l}\text { Vila Galé - Cumbuco } \\
\text { Golf Resort }\end{array}$ & Veraneio/turismo & $\begin{array}{l}\text { Hotel/lotes } \\
\text { residenciais/bangalôs }\end{array}$ & $\begin{array}{l}\text { Inauguração } \\
\text { em } 2010\end{array}$ \\
\hline Caucaia & $\begin{array}{l}\text { Cumbuco Beach } \\
\text { Resort }\end{array}$ & Veraneio/turismo & $\begin{array}{l}\text { Apartamentos/ } \\
\text { vivendas }\end{array}$ & Vendas \\
\hline Caucaia & $\begin{array}{l}\text { Brasil Real Cumbuco } \\
\text { Resort }\end{array}$ & Veraneio/turismo & $\begin{array}{l}\text { Condomínios/casas / } \\
\text { flats }\end{array}$ & $\begin{array}{l}30 \% \\
\text { concluído }\end{array}$ \\
\hline Caucaia & $\begin{array}{l}\text { Complexo Turístico } \\
\text { Dunas do Cumbuco }\end{array}$ & Veraneio/turismo & $\begin{array}{l}\text { Unidades } \\
\text { residenciais/ hotéis }\end{array}$ & Em estudo \\
\hline Beberibe & $\begin{array}{l}\text { Complexo turístico } \\
\text { Praia do Uruaú }\end{array}$ & Veraneio/turismo & $\begin{array}{l}\text { Hotel / lotes } \\
\text { residências }\end{array}$ & \\
\hline Beberibe & $\begin{array}{l}\text { Condominio Resort e } \\
\text { Spa Nascentes }\end{array}$ & Veraneio/turismo & $\begin{array}{l}\text { apartamentos/ } \\
\text { residências }\end{array}$ & 2 fase \\
\hline Beberibe & Resort Pestana Hotels & Veraneio/Turismo & $\begin{array}{l}\text { Hotel/villages/loteam } \\
\text { entos residenciais / } \\
\text { bangalôs }\end{array}$ & Em estudo \\
\hline Cascavel & $\begin{array}{l}\text { Balbino Beach e } \\
\text { Resort }\end{array}$ & Veraneio/turismo & $\begin{array}{l}\text { Hotel/apartamentos/ } \\
\text { unidades } \\
\text { habitacionais }\end{array}$ & $\begin{array}{l}\text { Projeto } \\
\text { aprovado }\end{array}$ \\
\hline Aracati & $\begin{array}{l}\text { Canoa Beachfront } \\
\text { resort }\end{array}$ & Veraneio & Casas/apartamentos & $\begin{array}{l}\text { Venda e } \\
\text { construção } \\
\end{array}$ \\
\hline Icapuí & $\begin{array}{l}\text { Empreendimento } \\
\text { Turístico Tremembé } \\
\text { Beach do Brasil }\end{array}$ & Veraneio/turismo & Hotel/ casas & $\begin{array}{l}\text { Em } \\
\text { construção }\end{array}$ \\
\hline Paraipaba & $\begin{array}{l}\text { Complexo Turístico } \\
\text { Lagoinha Suítes } \\
\text { Resort }\end{array}$ & Veraneio/turismo & $\begin{array}{l}\text { Hotel resort/casas } \\
\text { /chalés }\end{array}$ & $\begin{array}{l}\text { Obras } \\
\text { iniciadas em } \\
2005 \\
\end{array}$ \\
\hline Fortim & $\begin{array}{l}\text { Complexo turístico } \\
\text { imobiliário Playa } \\
\text { Mansa }\end{array}$ & Veraneio/Turismo & 4 hotéis/ residências & $\begin{array}{l}\text { Obras } \\
\text { Iniciadas em } \\
2006\end{array}$ \\
\hline
\end{tabular}

QUADRO 1 - RESORTS INSTALADOS NO CEARÁ E PROJETOS DE RESORTS RESIDENCIAIS. ORGANIZADO PELA AUTORA (2010).

FONTE: SEMACE (2012) / SETUR (2012).

Observação: Na pesquisa foram considerados os resorts que possuem acima de 100 unidades habitacionais.

Os resorts, de acordo com o quadro acima, elaborado através de análise dos dados da SETUR (2012) e SEMACE (2012), são ações que vêm se expandindo cada vez mais no cenário marítimo e turístico cearense. Como pode ser analisado, há previsão de um número considerável de futuros empreendimentos. Esses investimentos transformaram-se em um rápido crescimento de atividades turísticas e de veraneio, um processo que resulta em um aceleramento de mudanças espaciais no Ceará. 
O município de Aquiraz desde a década de 70 se destaca nas atividades de veraneio, tanto por sua proximidade com a capital como também pela abertura do município para com os empreendimentos turísticos (PEREIRA, 2006). Segundo o mesmo autor, Aquiraz recebeu o primeiro resort do Ceará em seu território, datado em 1988. Ainda menciona que foi com o PRODETUR que o Estado do Ceará, assim como os outros Estados do Nordeste tiveram o turismo consolidado, através de investimentos em infraestrutura, capacitação e qualificação do produto turístico.

É importante ressaltar que os outros municípios litorâneos do Estado do Ceará a partir de incrementos de políticas públicas de urbanização, se colocam também nesse novo modelo turístico do Ceará. Com destaque para municípios do litoral leste, pois estes dispõem de $70 \%$ dos resorts (porcentagem feita com a soma dos resorts instalados e projetos de resorts), litoral oeste com os outros 30\% e os próprios municípios metropolitanos de Aquiraz e Caucaia, que concentram a maioria desses investimentos tanto privados quanto públicos (SEMACE, 2012).

A segunda residência como propulsora de expansão urbana, junto à atividade do turismo, em empreendimentos de investimentos muitas vezes estrangeiros, com certeza é de suma importância para aceleramento do turismo e atração de investimentos privados tanto para compra como para venda.

Nas praias de Porto das Dunas e Prainha/Aquiraz o fenômeno dos resorts residenciais e sua espacialidade nessas áreas metropolitanas possibilitam a análise da dimensão da especulação imobiliária na área e a valorização dos terrenos, resultantes de investimentos públicos em equipamentos de infraestrutura (rodovias e eletricidade), principalmente em ruas que dão acesso para os grandes resorts (PEREIRA, 2006).

Os resorts caracterizam-se também como importantes empreendimentos para atração de investimentos estrangeiros, como pôde ser observado em uma análise da dinâmica, das atividades e da incorporação do veraneio ao turismo no resort Acqua Park (resort integrante do complexo Beach Park). O empreendimento Aquaville Resort situado na praia do Porto das Dunas - resort turístico residencial - tem em sua área um condomínio, onde os apartamentos são destinados a veraneio, possuem seus respectivos donos, e um hotel, onde este é propriamente turístico. O condomínio e o hotel possuem dinâmicas separadas. Mas tanto os veranistas como os turistas usam da mesma área de lazer e de outros equipamentos coletivos do resort. 
Por se tratar de um fenômeno ainda pouco discutido, e com a ainda escassez de literatura sobre o assunto, fica aqui uma explanação sobre os resorts e sua dinâmica nesses últimos parágrafos, como desafio lançado para pesquisas futuras em relação à incorporação do veraneio ao turismo, como essas duas atividades se unem para dominar e atrair cada vez mais investimentos estrangeiros e sua importância para as modificações do espaço, desafio proposto neste trabalho e para realizar pesquisas posteriores.

\section{CONSIDERAÇÕES FINAIS}

O turismo inserido na Região Nordeste do Brasil concentra-se, em maior parcela, na faixa litorânea e possui seu crescimento condicionado à valorização das paisagens litorâneas e da infraestrutura que lhe dá suporte.

Para tanto se torna importante desenvolver pesquisas como essa, num contexto que revele os investimentos públicos e privados que se hibridam no cenário turístico cearense e a importância dos resorts para as modificações sócio-espaciais na região metropolitana.

Além do desafio de comentar e pesquisar sobre um fenômeno novo, como os resorts residenciais, que estão cada vez mais presentes no cenário cearense, atraindo investimentos privados e uma contrapartida do Estado com suas políticas públicas de intensificação da atividade turística como alternativa de desenvolvimento econômico do Estado.

A pesquisa realizada e exposta nesse artigo não se conclui por si mesma, havendo a necessidade de buscar, analisar e interpretar cada vez mais a Vilegiatura Marítima e o Turismo como impulsionadores de valorização de espaços litorâneos e analisar o modificações ocorrentes no Estado na atualidade, e buscar fundamentos teórico-metodológicos que possam ajudar na compreensão das reestruturações do mercado e da reordenação do espaço, assim como, buscar elementos que possam responder as seguintes indagações:

- Quais as novas reestruturações do mercado imobiliário?

- O que é o Imobiliário-Turístico e quais as suas principais características? 
- O que é o turista residencial?

- E as redes hoteleiras? Qual o papel destas, na internacionalização dos lugares?

- Qual o papel das políticas públicas de turismo na produção do espaço e na reordenação dos territórios.

Portanto, há necessidade de interpretar os resorts residenciais, pois estes trazem novos elementos de análise, como a própria sinergia das atividades imobiliárias e as atividades do turismo, além da atração significativa de investidores e compradores internacionais, elementos que contribuem para reordenação dos espaços litorâneos na atualidade.

\section{REFERÊNCIAS}

ARAÚJO, E. F. Turismo na Metrópole: As implicações Espaciais no Litoral de Caucaia - CE. Fortaleza, 2009. Monografia (bacharelado em Geografia) apresentada ao Departamento de Geografia da Universidade Federal do Ceará.

BANCO DO NORDESTE DO BRASIL (BNB). Relatório Final do Prodetur I (primeira fase), 2010. Disponível em: <http://www.bnb.gov.br/content/aplicacao/prodetur /downloads/docs/avaliacao.prodetur_ne_i_polo_cd_200608.pdf >. Acesso em: 20/06/2012.

Comissão de Financiamento Externo (CONFIEX). Projetos Estados e Municípios, 2011. Disponível em: <http://www.planejamento.gov.br/secretarias/upload /Arquivos/seain /downloads/2012/120615_estados_e_municipios.pdf>. Acesso em: 05/06/2012.

CORIOLANO, L. N. M. T. O turismo nos discursos, nas políticas e no combate à pobreza. 1. ed. São Paulo: Anablumme, 2006. v. 1000. 238 p.

DANTAS, E. W. C.; PEREIRA, A. Q.; ARAUJO, E. F. de; PAULA, E. O. de. Turismo Litorâneo e Vilegiatura Marítima na Região Metropolitana de Fortaleza. In: 12 ENCUENTRO DE GEÓGRAFOS DE AMÉRICA LATINA, 2009, Montevidéu. Caminando en una América Latina en transformación, 2009. v. 1. p. 1-15.

DANTAS, E. W. C. Maritimidade nos Trópicos: por uma geografia do litoral. 1. ed. Fortaleza: Editora da Universidade Federal do Ceará, 2009. v. 1. 127 p.

GUIA DE RESORTS BRASILEIROS. São Paulo: On-line editora, n. 1 e 2, 2003. Disponível em: <http://www.resortsonline.com.br/pt> Acesso em: 15/06/2012. 
MELlO E SILVA, S. B. de; CARVALHO, S. S. de; SILVA, B. C. N. Globalização, Turismo e residência secundária: o exemplo de Salvador-Bahia e sua região de influência. Observatório de Inovação do Turismo - Revista Acadêmica, v. IV, n. 3, set./2009. 15 p.

MINISTÉRIO DO TURISMO (Mtur). Ações do PRODETUR s/a. Disponível em: $<$ http://www.turismo.gov.br/turismo/programas_acoes/regionalizacao_turismo/prodetur. html>. Acesso em: 16/06/2012.

PEREIRA, A. Q. Veraneio Marítimo e expansão metropolitana no Ceará. Fortaleza em Aquiraz. 2006. 157 f. Dissertação (mestrado). Universidade Federal do Ceará, Centro de Ciências, Departamento de Geografia, Programa de pós-graduação em geografia, 2006.

PROGRAMA DE ACELERAÇÃO DO CRESCIMENTO (PAC). Relatório do programa por estado, 2010. Disponível em: <www.brasil.gov.br/pac/>. Acesso em: $16 / 06 / 2012$.

SECRETARIA DE MEIO AMBIENTE DO CEARÁ (SEMACE). EIA RIMA. Licenciamentos de empreendimentos, ano 2012.

SECRETARIA DE TURISMO DO ESTADO DO CEARÁ (SETUR/CE). Rede hoteleira do interior, 2012. Disponível em: <http://www.setur.ce.gov.br/categorial/ copy4_of_estudos-e-pesquisas $>$. Acesso em: 15/06/2012.

SILVA, M. N. de. F. Incorporação do Veraneio às Atividades Turísticas na Região Metropolitana de Fortaleza (Ce). In: SEMINÁRIO GOVERNANÇA URBANA E DESENVOLVIMENTO METROPOLITANO, 2010, Natal. Anais... do seminário nacional governança urbana e desenvolvimento metropolitano, 2010. p. 1-14. ISBN: 978-85-61693-03-9.

Recebido em: 25-06-2012.

Aprovado em: 25-07-2012. 